\title{
Electroencephalographic Changes after Pediatric Cardiac Surgery with Cardiopulmonary Bypass: Is Slow Wave Activity Unfavorable?
}

\author{
BERNARD SCHMITT, BARBARA FINCKH, STEPHAN CHRISTEN, JENS LYKKESFELDT, \\ EDITH R. SCHMID, URS BAUERSFELD, HANNE CRITELLI, BEA LATAL HAJNAL, \\ PETER GESSLER, AND LUCIANO MOLINARI
}

\author{
University Children's Hospital [B.S., U.B., H.C., B.L.H., P.G., L.M.], CH-8032 Zürich, Switzerland; \\ University Children's Hospital [B.F.], D-20246 Hamburg, Germany; Institute for Infectious Diseases \\ [S.C.], University of Berne, CH-3010 Berne, Switzerland; Department of Pharmacology and Pathobiology \\ [J.L.], Royal Veterinary and Agricultural University, DK-1870 Copenhagen, Denmark; and Division of \\ Cardiovascular Anesthesia [E.R.S.], University Hospital, CH-8091 Zürich, Switzerland
}

\begin{abstract}
ABST
Pediatric cardiac surgery with cardiopulmonary bypass (CPB)
is frequently associated with neurologic deficits. We describe the
postoperative EEG changes, assess their possible causes, and
evaluate their relevance to neurologic outcome. Thirty-one chil-
dren and five neonates with congenital heart disease were in-
cluded. EEG recording started after intubation and continued
until $22-96$ h after CPB. In addition to conventional analysis,
spectral analysis was performed for occipital and frontal elec-
trodes, and differences between pre- and postoperative delta
power (delta- $\delta \mathrm{P}$ ) were calculated. Maximum values of occipital
delta- $\delta \mathrm{P}$ that occurred within 48 h after CPB were correlated
with clinical variables and with perioperative markers of oxida-
tive stress and inflammation. Occipital delta- $\delta \mathrm{P}$ correlated with
frontal delta- $\delta \mathrm{P}$, and maximum delta- $\delta \mathrm{P}$ correlated with conven-
tional rating. Distinct rise of $\delta \mathrm{P}$ was detected in 18 of 21 children
without any acute or long-term neurologic deficits but only in
five of 10 children with temporary or permanent neurologic
deficits. Furthermore, maximally registered delta- $\delta \mathrm{P}$ was in-
versely associated with duration of CPB and postoperative ven-
tilation. Maximal delta- $\delta \mathrm{P}$ was also inversely associated with the
\end{abstract}
loss of plasma ascorbate (as an index of oxidative stress) and plasma levels of IL-6 and IL-8. Slow wave activity frequently occurs within $48 \mathrm{~h}$ after CPB. However, our data do not support the notion that EEG slowing is associated with adverse neurologic outcome. This is supported by the fact that EEG slowing was associated with less oxido-inflammatory stress. (Pediatr Res 58: 771-778, 2005)

$\quad$ Abbreviations
AC, aortic cross-clamping
CPB, cardiopulmonary bypass
FFT, fast Fourier transformation
max delta- $\delta$ P, maximum difference between pre- and
postoperative delta power
MDA, malondialdehyde
MDA-TNL, malondialdehyde corrected for total neutral lipids
$\boldsymbol{\delta P}$, delta power
delta- $\boldsymbol{\delta P}$, difference between pre- and postoperative delta
power

Cardiac surgery with cardiopulmonary bypass (CPB) in children and neonates is frequently associated with acute neurologic symptoms and long-term neurologic deficits (1-4). Neuropsychological deficits persist in a substantial number of patients. During the intraoperative period, a global decrease in perfusion and oxygen delivery and focal ischemia related to

Received November 8, 2004; accepted January 28, 2005.

Correspondence: Bernhard Schmitt, M.D., Division of Clinical Neurophysiology, University Children's Hospital, Steinwiesstrasse 75, CH-8032 Zurich, Switzerland; e-mail: bernhard.schmitt@kispi.unizh.ch.

This study was partially supported by a grant from The National Institute of Neurological Sisorders and Stroke (R01 NS33997, S.C.) EMDO Stiftung Zurich, Switzerland (P.G.).

DOI: 10.1203/01.PDR.0000180554.16652.4E embolic insults or diffuse microvascular changes are the principal mechanisms of brain damage (5). Systemic inflammation and reactive oxygen species generated by CPB might contribute to postoperative neurologic dysfunction $(6,7)$. Impaired cerebral vasoregulation and ischemia/reperfusion injury continues in the early postoperative period $(8,9)$. Postoperative cardiopulmonary dysfunction may additionally threaten cerebral perfusion pressure and oxygen delivery. However, there is an increased energy demand to restore neuronal membrane function and ionic gradients that are compromised by CPB.

Events that affect the brain are usually followed by neuronal dysfunction, which can often be detected by EEG changes. The characteristic EEG pattern of brain injury caused by insults 
such as head trauma, hypoxia, or metabolic disturbances is the occurrence of dominant delta and slow delta activity. Slow wave activity after cardiac surgery with CPB has been suggested to reflect intra- and postoperative brain injury $(10,11)$. Furthermore, EEG may allow assessment of more subtle cerebral injury not severe enough to cause clinically apparent neurologic dysfunction (8). Quantification of slow wave activity therefore may be useful to explore the impact of different clinical and pathophysiologic variables on perioperative brain injury.

In the present study, we analyzed the changes in postoperative EEG by conventional and spectral analysis in children who underwent elective heart surgery with CPB. For assessing possible causes and the clinical relevance of these changes, they were compared with clinical variables, markers of oxidative stress and inflammation, and neurologic and developmental outcome.

\section{METHODS}

Patients. EEG postanalysis was performed in 36 children (including five neonates) who had congenital heart disease (median age 12 mo; range $6 \mathrm{~d}-70$ mo; Table 1) and underwent elective heart surgery with CPB. Thirteen of these children (1-13) were part of a placebo-controlled, randomized pilot study with dextromethorphan $(12,13)$. Twenty of the remaining 23 children (17-36) were

Table 1. Patient data

\begin{tabular}{|c|c|c|c|c|c|c|c|c|c|}
\hline No. & Gender & $\begin{array}{l}\text { Age at } \\
\text { OP } \\
\text { month }\end{array}$ & Vitium & $\begin{array}{l}\mathrm{CPB} \\
\min .\end{array}$ & $\begin{array}{l}\text { AC } \\
\text { clamp } \\
\text { min. }\end{array}$ & $\begin{array}{l}\text { Vent. } \\
\text { hours }\end{array}$ & $\begin{array}{c}\text { Postoperative (within } 3 \mathrm{mo} \text { ) } \\
\text { problems, persistent neurological } \\
\text { deficits are underlined }\end{array}$ & $\begin{array}{l}\text { IQ } \\
\text { before } \\
\text { OP }\end{array}$ & $\begin{array}{c}\text { IQ } \\
\text { after } \\
\text { OP }\end{array}$ \\
\hline 1 & $\mathrm{~F}$ & 7 & Tetralogy of Fallot & 115 & 46 & 456 & Stupor, no eye contact, CHF, low BP, & 84 & 87 \\
\hline 2 & M & 3 & Tetralogy of Fallot & 101 & 48 & 672 & $\begin{array}{l}\text { Dystonia, right hemiparesis, } \\
\text { stereotypic movements, myoclonus, } \\
\text { CHF, low BP }\end{array}$ & 90 & 63 \\
\hline 3 & M & 35 & Tetralogy of Fallot & 102 & 30 & 73 & Tremor, CHF & 100 & 115 \\
\hline 4 & $\mathrm{~F}$ & 34 & Multiple VSD, pulmon. stenosis & 91 & 41 & 138 & Sepsis & 100 & 89 \\
\hline 5 & M & 34 & Tetralogy of Fallot & 116 & 28 & 211 & & 86 & 92 \\
\hline 6 & M & 10 & Perimembranous VSD with malignment & 74 & 33 & 99 & & 94 & 89 \\
\hline 7 & M & 6 & Perimembranous VSD & 156 & 67 & 240 & & 110 & 90 \\
\hline 8 & M & 4 & Multiple VSD & 128 & 53 & 1414 & $\mathrm{CHF}$ & 90 & 100 \\
\hline 9 & $\mathrm{~F}$ & 11 & Perimembranous VSD & 79 & 33 & 120 & & 100 & 97 \\
\hline 10 & $\mathrm{~F}$ & 19 & Tetralogy of Fallot & 98 & 50 & 51 & & 104 & 98 \\
\hline 11 & M & 14 & $\begin{array}{l}\text { Perimembranous VSD, right ventricular } \\
\text { muscle bundle, subaortic ridge }\end{array}$ & 104 & 54 & 56 & & 105 & 96 \\
\hline 12 & $\mathrm{~F}$ & 12 & Tetralogy of Fallot & 137 & 80 & 94 & & 97 & 98 \\
\hline 13 & M & 29 & Doubly committed VSD & 44 & 23 & 52 & $\begin{array}{l}\text { Seizure during transport, slight } \\
\text { hemiparesis }\end{array}$ & 84 & 88 \\
\hline 14 & M & 8 & Perimembranous VSD & 64 & 30 & 9 & Tetraplegia & 109 & \\
\hline 15 & M & 2 & $\begin{array}{l}\text { VSD, sinus venosus defect, partial } \\
\text { anomalous pulmonary venous } \\
\text { drainage, mitral stenosis }\end{array}$ & 207 & 55 & 1341 & $\begin{array}{l}\text { Seizures after } 3 \text { wks, restlessness, } \\
\text { CHF }\end{array}$ & 88 & \\
\hline 16 & $\mathrm{~F}$ & 15 & Tetralogy of Fallot & 83 & 29 & 264 & $\begin{array}{l}\text { Chorea, stupor, no eye contact, oral } \\
\text { automatism, sepsis, hepatic } \\
\text { insufficiency }\end{array}$ & 91 & 70 \\
\hline 17 & $\mathrm{~F}$ & 56 & Tricuspid atresia & 69 & - & 11 & Sepsis & 88 & 82 \\
\hline 18 & M & 9 & VSD & 105 & 38 & 16 & Sepsis, seizures $>48 \mathrm{~h}$ post $\mathrm{CPB}$ & 102 & 105 \\
\hline 19 & $\mathrm{~F}$ & 62 & ASD & 39 & - & 4 & & 76 & 84 \\
\hline 20 & M & 10 & VSD & 77 & 41 & 77 & & 70 & 62 \\
\hline 21 & $\mathrm{~F}$ & 12 & Double inlet left ventricle & 45 & - & 79 & & 105 & 103 \\
\hline 22 & $\mathrm{~F}$ & 53 & Primum ASD & 114 & 63 & 5 & & 84 & 90 \\
\hline 23 & M & 9 & VSD & 122 & 42 & 21 & & 84 & 93 \\
\hline 24 & $\mathrm{~F}$ & 53 & Coarctation of the aorta & 32 & 26 & 7 & & 112 & 111 \\
\hline 25 & M & 66 & VSD & 69 & 28 & 6 & & 79 & 83 \\
\hline 26 & $\mathrm{~F}$ & 9 & VSD & 197 & 77 & 177 & Chorea, oral automatism, pneumonia & 82 & 83 \\
\hline 27 & $\mathrm{~F}$ & 18 & Atrioventricular septal defect & 193 & 86 & 432 & $\begin{array}{l}\text { Oral automatism, tremor, restlessness, } \\
\quad \mathrm{CHF}\end{array}$ & 64 & 62 \\
\hline 28 & $\mathrm{~F}$ & 54 & $\begin{array}{l}\text { Pulmonary atresia and intact ventricular } \\
\text { septum }\end{array}$ & 93 & 7 & 22 & & 82 & 89 \\
\hline 29 & M & 2 & VSD & 75 & 36 & 72 & & & 90 \\
\hline 30 & $\mathrm{~F}$ & 56 & Double inlet left ventricle & 152 & - & 19 & & 88 & 86 \\
\hline 31 & M & 70 & VSD & 84 & 38 & 7 & & 109 & 132 \\
\hline 32 & M & $6 \mathrm{~d}$ & Transposition of the great arteries & 180 & 76 & 72 & & & 90 \\
\hline 33 & $\mathrm{~F}$ & $16 \mathrm{~d}$ & Transposition great arteries, VSD & 181 & 157 & 144 & Myocardial infarct & & 111 \\
\hline 34 & M & $29 d$ & Truncus arteriosus & 190 & 81 & 168 & $\begin{array}{l}\text { Periodic stiffness, asymmetric } \\
\text { movements, resuscitation } 48 \text { h post } \\
\text { OP }\end{array}$ & & 98 \\
\hline 35 & M & $7 \mathrm{~d}$ & Double inlet left ventricle & 162 & 87 & 227 & & & 90 \\
\hline 36 & M & $18 \mathrm{~d}$ & Aortopulmonary window & 150 & 39 & 336 & Sepsis & & \\
\hline
\end{tabular}

$\mathrm{VSD}=$ ventricular septal defect, $\mathrm{ASD}=$ atrial septal defect, $\mathrm{CHF}=$ congestive heart failure, $\mathrm{BP}=$ blood pressure. 
part of a comprehensive study that analyzed intra- and postoperative indices of systemic oxidative stress and inflammation (14). None of these studies included children with noncardiac malformations and apparent preoperative neurologic abnormalities. Written informed consent was obtained from the parents of the children, and both studies were approved by the Ethical Committee of the University Children's Hospital of Zurich.

Anaesthetic and CPB procedures. Anesthesia was induced with halothane or sevoflurane, nitrous oxide, oxygen, and pancuronium. After endotracheal intubation, anesthesia was maintained with flunitrazepam or midazolam and fentanyl or sufentanil. CPB was performed with a roller pump, a membrane oxygenator, and an arterial filter. In 32 children, CPB surgery was performed under hypothermic conditions (rectal temperature between 21 and $32^{\circ} \mathrm{C}$ ), and low-flow CPB was used in two children (33 and 35). Normothermic CPB surgery was performed in four children $(17,19,21$, and 30). Age-related perfusion rate was $100-200 \mathrm{~mL} \cdot \mathrm{kg}^{-1} \cdot \mathrm{min}^{-1}$ during normothermia, and pump flow was gradually reduced as temperature decreased. Alpha stat acidbase management was used, and adequacy of pump flow was monitored by intermittent determination of arterial and venous oxygen saturation. In al children with body weight $\leq 8 \mathrm{~kg}$, prednisolone $(30 \mathrm{mg} / \mathrm{kg}$ ) was added to the priming solution of the CPB circuit. Six children were treated with dextromethorphan $35 \mathrm{mg} \cdot \mathrm{kg}^{-1} \cdot \mathrm{d}^{-1}$ (12). Postoperative sedation and pain management was performed with flunitrazepam, midazolam, chloralhydrate, nalbuphine, nicomorphine, morphine, and sufentanil.

EEG recording and analysis. Pre-, intra-, and postoperative EEG recordings were obtained on a standard 21-channel system (Neurofile/Coherence IT-med GmbH, Usingen, Germany). The EEG signals were amplified (time constant $10 \mathrm{~s}$, low-pass filter up to $300 \mathrm{~Hz}$ ), A/D-converted (sample rate $1 \mathrm{kHz}$, resolution 12 bit), and after digital anti-aliasing filtering stored with 128 samples/s. Preoperative EEG was generally performed in the week preceding cardiac surgery; in six children, the preoperative EEG was performed 12-86 d before surgery because operation was postponed. Intraoperative recording started after intubation and was continued until 22-96 h (mean $54 \mathrm{~h}$ ) after CPB. EEG was suspended only for transportation of the patient to and from the intensive care unit. During the recording, electrodes were checked twice daily and adjusted when necessary.

EEG was analyzed in terms of age-appropriate background activity. The occurrence of sleep pattern (spindles and $\mathrm{K}$ complexes) was registered. Localized rhythmic paroxysmal activity longer than $5 \mathrm{~s}$ was classified as electrographic seizure. Sharp/spike waves (transients, clearly distinguished from background activity and from artifacts, $70-200 \mathrm{~ms}$ duration) were considered when they occurred repeatedly. EEG results were classified according to a rating scheme shown in Table 2. Neonatal EEGs $(<44$ wk gestational age $)$ were rated essentially as described by Sarnat and Sarnat (14).

From artifact-free preoperative and the entire postoperative records, 2-s epochs from occipital (O1 and $\mathrm{O} 2$ ) and frontal (F3 and F4) electrodes, registered to a common average reference, were fast Fourier transformed (FFT), and absolute power for the $\delta(0.1-3.5 \mathrm{~Hz}), \theta(4.0-7.5 \mathrm{~Hz}), \alpha(8.0-12.5$ $\mathrm{Hz})$, and $\beta(13.0-30.0 \mathrm{~Hz})$ frequency bands was calculated. $\mathrm{O} 1$ and $\mathrm{O} 2$ electrodes were selected because visual analysis revealed abnormalities of the background activity predominantly over the posterior region. F3 and F4 were selected to assess the corresponding changes over the anterior part of the brain.

For graphic display, we calculated successive mean values of power over 500 epochs (16 min, $40 \mathrm{~s}$ ) and over all preoperative epochs. Power data were $\log$ transformed, and occipital and frontal differences between pre- and postoperative delta power (delta- $\delta \mathrm{P}$ ) were plotted versus time after CPB. Distinct and prolonged differences within the electrode pairs or marked deviations from an obvious delta- $\delta \mathrm{P}$ trend were suspected to be artifactual. Such sections occurred in eight children $(18,20,24,29-31,35$, and 36), were reviewed in the original EEG, and were excluded when artifacts were detected. In Table 3, we took antilogarithms of delta- $\delta \mathrm{P}$ and presented the postoperative $\delta \mathrm{P}$ as percentage of the preoperative $\delta \mathrm{P}$.

For the assessment of associations between delta- $\delta \mathrm{P}$ and intra- and postoperative variables or neurologic outcome, the largest difference in occipital $\delta \mathrm{P}$ (max delta- $\delta \mathrm{P}$ ) that occurred within the first $48 \mathrm{~h}$ after $\mathrm{CPB}$ was used. For this purpose, we split the EEG into 12-h sections, calculated a mean value of both occipital delta- $\delta \mathrm{P}$ of each section, and selected the largest delta- $\delta \mathrm{P}$. This procedure was necessary because short-term artifacts sometimes distorted single 500 epochs mean values, providing unreliably high delta- $\delta \mathrm{P}$. For correlation between occipital and frontal delta- $\delta \mathrm{P}$ and between delta- $\delta \mathrm{P}$ and the visual rating, we used the 12-h mean values of both occipital and both frontal delta- $\delta \mathrm{P}$. Because alterations of neuronal function in neonates are reflected in a discontinuous and periodic pattern and not in changes of $\delta \mathrm{P}$, they were excluded from this calculation (see "Results").

Clinical examinations. A standard neurologic examination and developmental test was done before surgery and 3-8 mo after surgery. Developmental testing was performed in 30 of 36 children before operation and in 33 of 34 children who survived surgery. One child experienced postoperative tetraplegia, and developmental testing was not possible. Twenty-eight children were examined pre- and postoperatively. During the first postoperative days, the general clinical condition, alertness, and occurrence of neurologic symptoms were recorded daily. In patients $1-13$, the German version (15) of the Griffith Developmental Scales (16) was used in children who were younger than $2 \mathrm{y}$, and the Snijder's Oomen Nonverbal Intelligence test was used in the older ones. In patients 14-36, the Bayley Scales of Infant Development II (41) were applied to children up to $3 \mathrm{y}$ of age, and the Snijder's Oomen Nonverbal Intelligence Test Revised was used for children between 3 and 6 y of age (17).

Correlation with markers of oxidative stress and inflammation. EEG changes were compared with markers of oxidative stress and inflammation determined in a separate study to be published elsewhere (14a ). In this study, levels of antioxidants (e.g. ascorbate), oxidized proteins (carbonyls), oxidized lipids [malondialdehyde (MDA)], and several proinflammatory cytokines (tumor necrosis factor- $\alpha$, IL-6, and IL-8) were analyzed in plasma samples that were obtained from patients $17-36$ at different points of surgery [right before surgery (baseline); $5 \mathrm{~min}$ after declamping of the aorta [in four children (17, 19,21 , and 30) at the end of CPB]; and 3-12 h, $24 \mathrm{~h}$, and $48 \mathrm{~h}$ after CPB). For correlation with EEG data, we used only markers that showed substantial intraand postoperative changes: ascorbate, MDA corrected for total neutral lipids (MDA-TNL), plasma carbonyls, IL-6, and IL-8. Ascorbate and MDA were measured by HPLC as described previously $(18,19)$, and IL-6 and IL-8 were measured by cytometric bead array analysis.

Plasma sodium. Plasma sodium was measured several times daily as part of the laboratory routine.

Statistical analysis. Calculations and graphics were carried out by Excel 97 (Microsoft, Seattle, WA) and S-PLUS 2000 for Windows (Insightful Corporation, Seattle, WA). Pearson correlations were calculated between max delta- $\delta \mathrm{P}$ and biochemical parameters.

\section{RESULTS}

Thirty-four of 36 enrolled children survived. One child (36) died 2 wk after surgery as a consequence of intraoperative complications, and another child (15) died after 5 mo during reoperation.

Neurologic and developmental results. Acute neurologic deficits after surgery occurred in 10 children and one neonate (31\%) and included dystonia, chorea, automatism, tremor, seizures, lack of eye contact, asymmetric movements, and paresis (Table 1). Neurologic sequelae persisted in two children and included slight hemiparesis in one child (13) and tetraplegia caused by spinalis anterior infarction in another child (14). Three surviving (11\%) children received a postoperative diagnosis of mental retardation (IQ score $<70$ ), and five $(15 \%)$ children received a postoperative diagnosis of mild

Table 2. EEG rating

\begin{tabular}{|c|c|c|}
\hline Score & Children & Neonates ( $<44$ weeks gestational age $)$ \\
\hline 1 & Normal or mildly abnormal background activity & Continuous activity \\
\hline 2 & Moderate disturbance of background activity (dominant delta) & $\begin{array}{l}\text { Periodic pattern, polymorphic sharp and slow } \\
\text { waves, bursts ( } 1-3 \text { s) alternated with low } \\
\text { amplitude delta/theta (3-6 s) ("dysmature") }\end{array}$ \\
\hline 3 & Severe disturbance of background activity (dominant slow delta) & $\begin{array}{l}\text { Bursts: excessive asynchronous between } \\
\text { hemispheres, burst frequency every } 6-12 \mathrm{~s} \\
\text { Low amplitude intervals: isopotential }\end{array}$ \\
\hline
\end{tabular}


Table 3. Postoperative EEG: rating and $12 \mathrm{~h}$ mean values of differences between pre-and postoperative occipital delta power (in percentage of preoperative $\delta P$ )

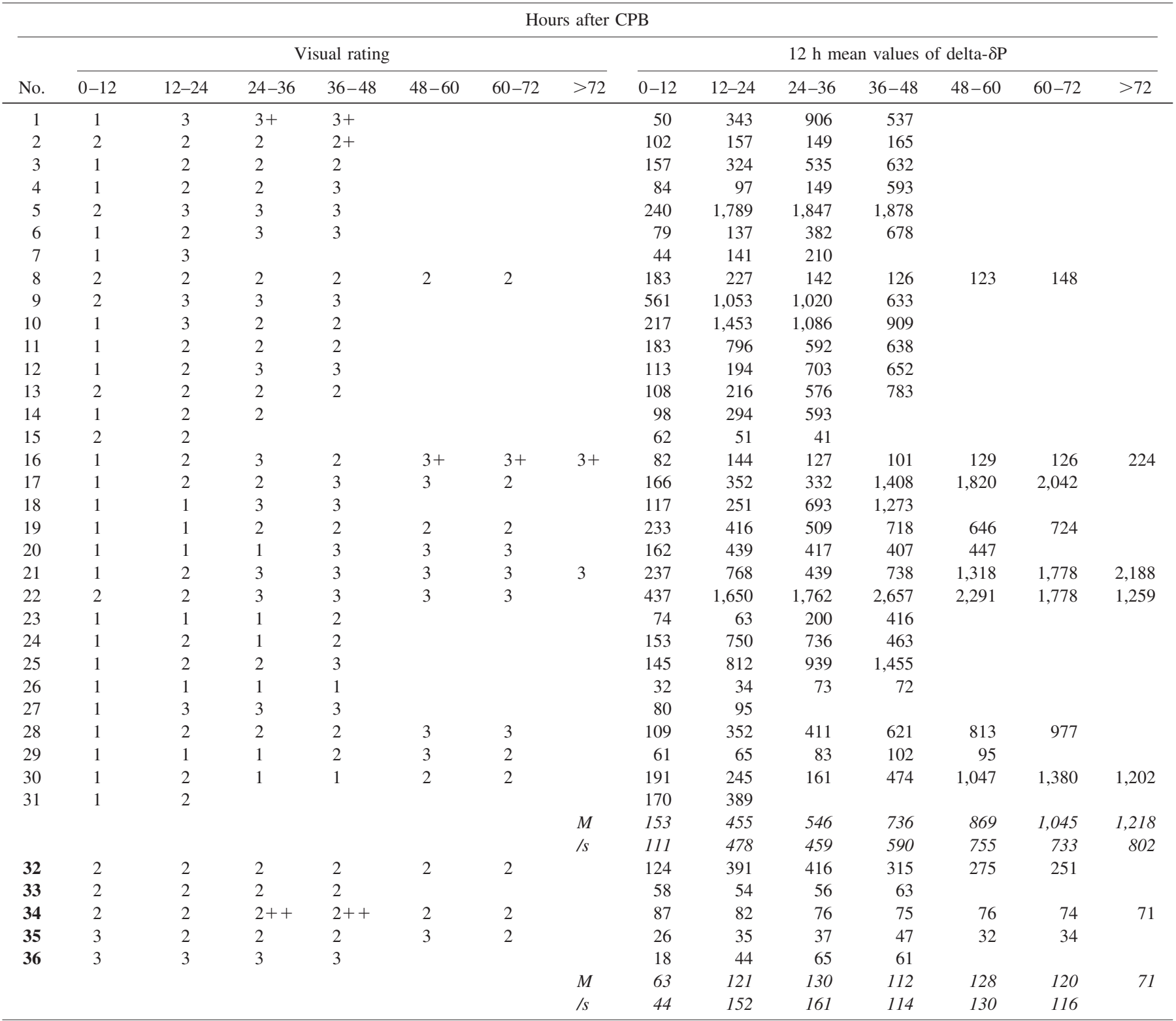

$\mathrm{m} / \mathrm{s}=$ mean/standard deviation

+ Episodes with intermittent suppression

++ Suppression-burst or isoelectric EEG or distinct low voltage

developmental delay (IQ score 70-85). Developmental scores were unchanged ( $\geq 7.5$ IQ scores difference) in $17(61 \%)$ of 28 children, declined in six children, and improved in five.

EEG analysis. EEG seizures without clinical symptoms were registered in three children, starting between 9 and $36 \mathrm{~h}$ after CPB. One child (34) with a single EEG seizure subsequent to mechanical resuscitation showed temporary neurologic deficits but normal development 6 mo later. The other two children (16 and 36) had repeated seizures over several hours and days. Both children had intraoperative complications with isoelectric EEG $>100 \mathrm{~s}$ during normothermia. One child (36) died after $14 \mathrm{~d}$. The other one (16) showed distinct neurologic symptoms that gradually improved over several months. After 6 mo, developmental score was lower than preoperatively but recovered when retested 18 mo after CPB.
Increased focal and multifocal sharp waves without electrographic seizures were observed in 11 patients. In only three children $(1,2$, and 3$)$ were sharp waves associated with acute neurologic symptoms.

Preoperative EEG background activity was normal in three of five neonates and in 30 of 31 older children (Table 3). Two neonates (33 and 36) showed discontinuous periodic patterns, and one child (19) showed intermittent slowing of background activity. After surgery (Table 3), EEG was moderately abnormal in three (32-34) and severely abnormal in two (35 and 36) neonates. In the older children, abnormal background activity increased slowly during the first postoperative hours and days. In the first $12 \mathrm{~h}$, only seven (22\%) of 31 children showed moderate or severe (grades 2 and 3) slowing of background activity. The number increased to $15(48 \%)$ of 31 between 12 
and $24 \mathrm{~h}$ and to $26(93 \%)$ of 28 between 24 and $48 \mathrm{~h}$. All children with EEG registration beyond $48 \mathrm{~h}$ demonstrated moderate or severe slowing of background activity. Lowvoltage activity or suppression-burst was not seen in our patients. Intermittent suppression alternating with severe abnormality of the background activity occurred in three children (1, 2 and 16) always beyond $24 \mathrm{~h}$ after CPB. In one child (34), two episodes of isoelectric EEG of $\sim 100 \mathrm{~s}$ duration were registered, once during mechanical resuscitation followed by a single electrographic seizure (see above).

Description of the FFT data. Diagrams of postoperative power revealed almost identical occipital and frontal delta- $\delta \mathrm{P}$ in 22 children (Fig. 1). Twelve children showed higher occipital delta- $\delta \mathrm{P}$, and two children showed higher frontal delta- $\delta \mathrm{P}$. Correlation between occipital and frontal max delta- $\delta \mathrm{P}$ was 0.85 ( $p<0.001$; all children included), and max delta- $\delta \mathrm{P}$ of both electrodes correlated with the conventional rating $(0.62 ; p$ $<0.001$; neonates excluded).

Postoperative $\delta \mathrm{P}$ distinctly increased $(389-2188 \%)$ in 24 children (including one neonate) and reached its maximum between 12 and $24 \mathrm{~h}$ in five children, between 24 and $48 \mathrm{~h}$ in 13 children, and after $48 \mathrm{~h}$ in six children (Table 3 ). No or only a minimal increase of $\delta \mathrm{P}(102-227 \%)$ was observed in five children $(2,7,8,16$, and 29), and $\delta \mathrm{P}$ always below the preoperative values $(<100 \%)$ occurred in four of five neonates (33-36) and in three of 31 older children (15, 26, and 27).

The magnitude of delta- $\delta \mathrm{P}$ tended to depend on age. Whereas in older children mean $\delta \mathrm{P}$ stepwise increased from
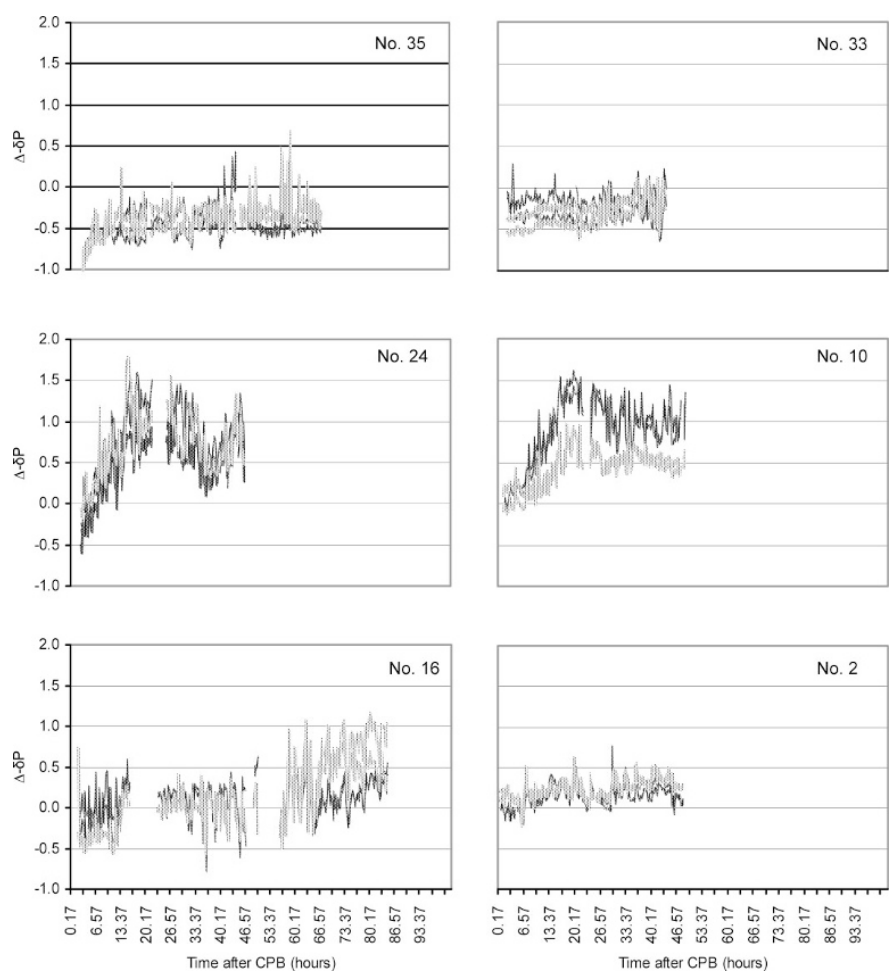

Figure 1. Postoperative $\delta \mathrm{P}$ over both occipital (dark lines) and both frontal (bright lines) electrodes. Patients 35 (age $7 \mathrm{~d}$ ) and 33 (age $16 \mathrm{~d}$ ): $\delta \mathrm{P}$ below the preoperative values, no increase; patient 24 (age $53 \mathrm{mo}$ ): distinct increase of $\delta \mathrm{P}$; patient 10 (age $19 \mathrm{mo}$ ): increase of occipital $\delta \mathrm{P}>$ increase of frontal $\delta \mathrm{P}$; patient 16 (age $15 \mathrm{mo}$ ): minimal increase after $60 \mathrm{~h}$, frontal delta- $\delta \mathrm{P}>$ occipital delta- $\delta \mathrm{P}$; patient 2 (age $3 \mathrm{mo}$ ): minimal increase of $\delta \mathrm{P}$.
$153 \%$ in the first $12 \mathrm{~h}$ to $736 \%$ between 36 and $48 \mathrm{~h}$ and to $1218 \%$ after $72 \mathrm{~h}$, the respective values in neonates achieved only 63,112 , and $71 \%$ (Table 3 ). Also, in the first 2 y of life, postoperative max delta- $\delta \mathrm{P}$ tended to increase. Postoperative $\theta$, $\alpha$, and $\beta$ power were mostly unchanged or below the preoperative values.

delta- $\delta P$ and intra- and postoperative variables. Thirty-one children (excluding neonates) were used to study possible associations between delta- $\delta \mathrm{P}$ and intra- and postoperative variables (including neurologic outcome). Occipital delta- $\delta \mathrm{P}$ was lower when artificial ventilation was prolonged $(p=$ 0.002 ; Fig. $2 A$ ). Fourteen children had their max delta- $\delta \mathrm{P}$ during ventilation, and 11 children had it after extubation. Children with minimal or without increase in $\delta \mathrm{P}$ all were ventilated beyond the EEG registration. Occipital max delta- $\delta \mathrm{P}$ was inversely associated with duration of $\mathrm{CPB}(p=0.002$; Fig. $2 B$ ) and showed a trend to lower values with increasing duration of aortic cross-clamping (AC; Fig. $2 C$ ). Four children $(2,14,15$, and 16) with intraoperative complications, reflected by isoelectric EEG $>50 \mathrm{~s}$ during normothermia, showed no or minimal $(62-141 \%)$ increase of $\delta \mathrm{P}$ after surgery. Children with postoperative cardiopulmonary or septic problems (neonates excluded) showed less frequently delta- $\delta \mathrm{P}>300 \%$ (five of 11 children) than children without such complications (18 of 20 children; $p=0.01$ ).

Occipital max delta- $\delta \mathrm{P}$ was negatively correlated with the loss of plasma ascorbate immediately after aorta declamping/ pump switch-off in patients with partial CPB $(p<0.05$; Table $4)$. No correlations were found between occipital max delta- $\delta P$ and MDA-TNL or plasma carbonyls. However, occipital max delta- $\delta$ P inversely correlated with IL-6 levels at 24 and $48 \mathrm{~h}$ after CPB $(p<0.05)$ and with IL-8 levels after declamping and at 24 and $48 \mathrm{~h}$ after CPB (all $p<0.01$ ).

Postoperative plasma sodium was consistently $>134 \mathrm{mM}$ in 31 patients. Five children showed single values between 131 and $133 \mathrm{mM}$. Max delta- $\delta \mathrm{P}$ was not different in children who received dextromethorphan.

Increase of $\delta \mathrm{P}(>300 \%)$ was detected in 18 of 21 children without any neurologic deficits but only in five of 10 children with temporary or permanent neurologic deficits $(p=0.07$, Fisher Exact test). With respect to the changes in developmental scores, increase of $\delta \mathrm{P}(>300 \%)$ was detected in four of five children with increased scores and in three of six children with reduced developmental scores $(p=0.5)$.

\section{DISCUSSION}

This study has shown that distinct slowing of EEG activity frequently occurs within $48 \mathrm{~h}$ after cardiac surgery with CPB. Our data do not support the notion that this EEG slowing is associated with adverse neurologic outcome. This is supported by the fact that EEG slowing was more prominent in children with less oxidative stress and inflammation and shorter duration of CPB.

Postoperative EEG. The EEG slowing appears several hours after surgery and persists for several days. Similar EEG alterations after cardiac surgery have been reported by Pampiglione (20) and by Sachdev et al. (21). Both reported that the alter- 
A

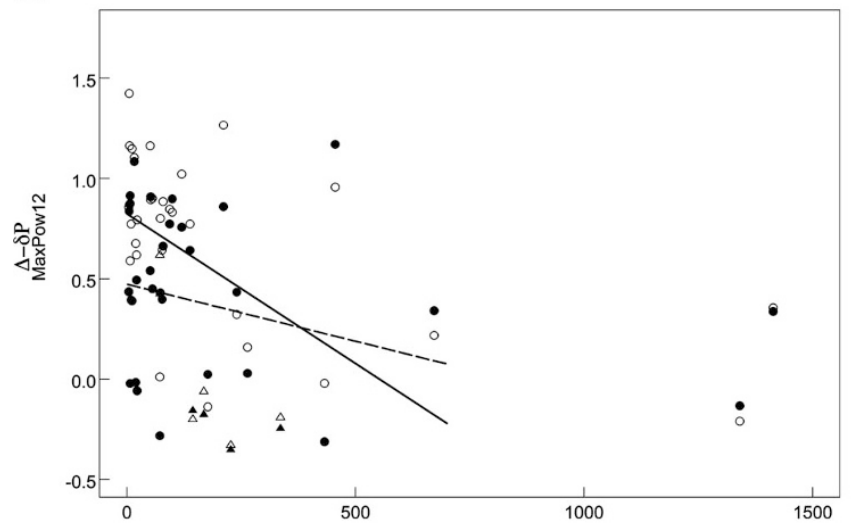

B

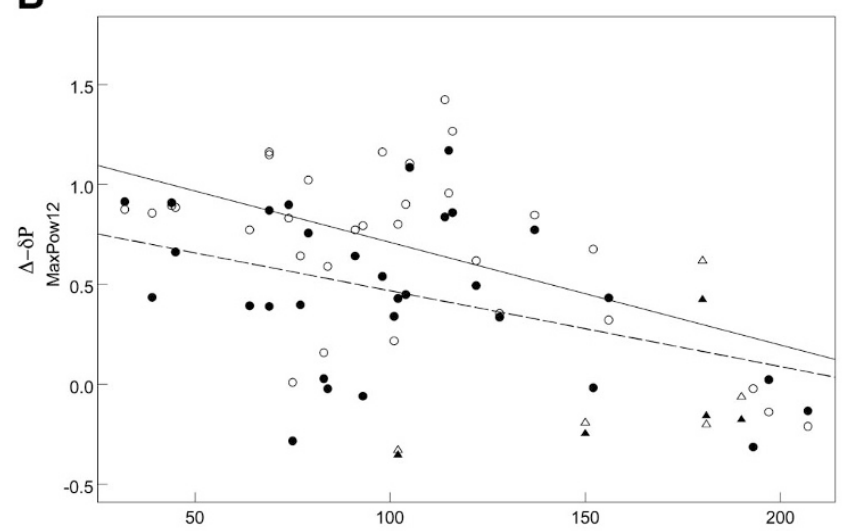

C

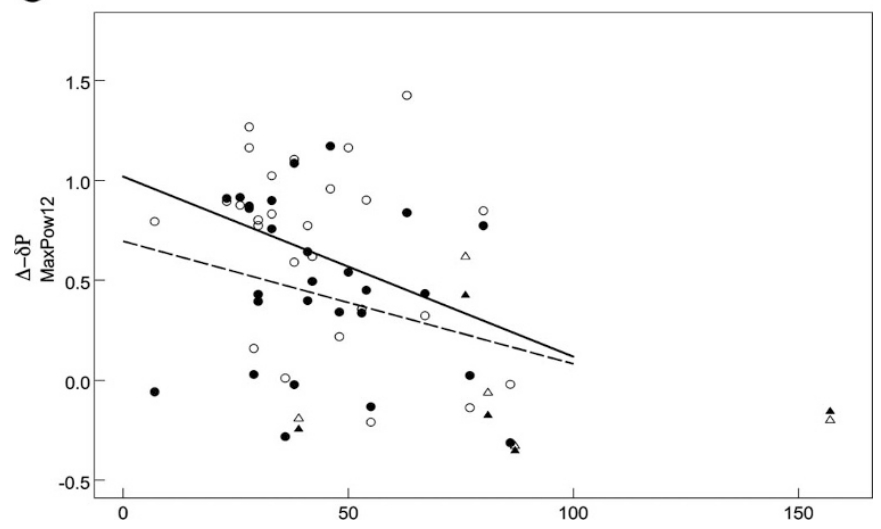

Figure 2. Correlation of occipital and frontal max delta- $\delta \mathrm{P}$ with duration of postoperative ventilation (occipital: $r=-0.54, p=0.002$; frontal: $r=-0.25$, $p=0.2 ; A$ ), CPB (occipital: $r=-0.54, p=0.002$; frontal: $r=-0.42, p=$ $0.02 ; B$ ), and AC (occipital: $r=-0.37, p=0.06$; frontal: $r=-0.21, p=0.3$; $C)$. Decreasing max delta- $\delta \mathrm{P}$ with increasing duration. Occipital max delta- $\delta \mathrm{P}$ is indicated by empty circles and triangles, frontal max delta- $\delta \mathrm{P}$ by black circles and triangles, and newborns (not included in the calculation of the correlations) by triangles. Extreme values were not included in the calculation of the correlations. Regression lines are continuous for occipital and dashed for frontal.

ations begin to appear on the second postoperative day, increase for a few days, and usually return to the preoperative EEG pattern $~ 5-10 \mathrm{~d}$ after the operation. Little, if any, change was seen on the first postoperative day. This cycle of EEG changes was seen in most children (20) and adults (21). The increase of slow activity occurs over both hemispheres and tends to be greater in the posterior than in the anterior half of
Table 4. Correlation between occipital max delta- $\delta P$ and markers of oxidative stress and inflammatory response (without neonates)

\begin{tabular}{lllrrc}
\hline & $\begin{array}{c}\text { Number of } \\
\text { patients }\end{array}$ & $\begin{array}{c}\text { Post } \\
\text { CPB }\end{array}$ & $\begin{array}{c}3-12 \mathrm{~h} \\
\text { post CPB }\end{array}$ & $\begin{array}{c}24 \mathrm{~h} \\
\text { post CPB }\end{array}$ & $\begin{array}{c}48 \mathrm{~h} \\
\text { post CPB }\end{array}$ \\
\hline Ascorbate loss & 15 & $-0.52^{*}-0.49$ & -0.34 & -0.29 \\
MDA mmol/mol TNL & 15 & -0.33 & -0.33 & -0.43 & 0.07 \\
Carbonyls nmol/mg & 15 & -0.05 & 0.03 & 0.36 & 0.40 \\
$\quad$ protein & & & & & \\
IL $6 \mathrm{pg} / \mathrm{ml}$ & $12-15$ & -0.47 & -0.11 & $-0.53^{*}$ & $-0.56^{*}$ \\
IL $8 \mathrm{pg} / \mathrm{ml}$ & $12-15$ & $-0.68^{* *} 0.50$ & $-0.73^{* *}$ & $-0.67^{* *}$ \\
\hline
\end{tabular}

Ascorbate values were calculated as the percent difference to presurgical (baseline) values

$* p=0.05 ; * * p=0.01$.

After aorta declamping pump switch-off

the brain (20). Hauser et al. (22) investigated quantitative EEG before, 6 and $11 \mathrm{~d}$ after, and 6 wk after $\mathrm{CPB}$ surgery and demonstrated an increase in the delta band on the sixth postoperative day, with a successive decrease to preoperative values after 6 wk. Sotaniemi (10) reported abnormal EEG $10 \mathrm{~d}$ after valve replacement surgery in $67-97 \%$ of adult patients, which improved in the following months. Quantitative EEG in beagle puppies, recorded $6 \mathrm{~d}$ after circulatory arrest or lowflow CPB, revealed a significant increase in delta activity when cooled to $18^{\circ} \mathrm{C}$ but no significant increase after circulatory arrest at 8 and $13^{\circ} \mathrm{C}(8)$.

Neonates showed visually different postoperative EEGs, characterized by a periodic pattern. In our study, only one neonate showed an increase of slow wave activity similar to that of older children. These results were confirmed by FFT analysis demonstrating unchanged or negative delta- $\delta \mathrm{P}$ in four neonates and increase of $\delta \mathrm{P}$ in one. Abnormalities in EEG background activity are different in neonates, compared with older children: diffuse delta patterns are very rare, and the major background abnormalities are electrocerebral inactivity, burst-suppression pattern, marked excessive discontinuity, or low-voltage activity (23).

Beyond the neonatal period, the magnitude of delta- $\delta \mathrm{P}$ seems to depend on the maturity of the brain, with rising values in the first $2 \mathrm{y}$ of life. This is in accordance with the findings of Pampiglione (20), who reported more pronounced EEG slowing in children aged between 2 and $7 \mathrm{y}$. Postoperative EEG seizures, registered in three patients, where always preceded by episodes of normothermic isoelectric EEG, indicating a substantial brain affecting event. The outcome of two patients, with death or neurologic deficits, is comparable with that described in published reports $(2,24)$.

Postoperative EEG and neurologic deficits. Half of the children with postoperative neurologic and developmental deficits showed absent or minor slow wave activity in EEG, whereas almost all children without such deficits demonstrated the distinct slowing of EEG. Lack of abnormal neurologic signs during abnormal postoperative EEG were reported in two clinical $(20,22)$ and one animal (8) study. Others reported neurologic deficits at approximately the same time as the EEG became abnormal $(10,11,21)$ and unfavorable neurologic outcome when background activity was severely abnormal (11). One possible explanation for this discrepancy is the time point of the postoperative EEG slowing. It is conceivable that slow 
wave activity that persists beyond the seventh to 10th postoperative day may have other implications on prognosis than temporary slowing in the first $5 \mathrm{~d}$. Prolongation of EEG monitoring up to $10 \mathrm{~d}$ may provide more information on the regression of the early EEG slowing and on the validity of persistent slowing for the neurologic outcome prognosis.

EEG slowing and intra- and postoperative variables. Several sources have been considered as possible causative factors for the EEG slowing after cardiac surgery, but, thus far, it has not been possible to correlate abnormalities of these factors with the slowing. Pampiglione (20) suspected low plasma sodium as the underlying cause and found EEG changes that were much greater when plasma sodium was below 128-130 mEq. In our study, postoperative plasma sodium was almost constant, with values $>134 \mathrm{mM}$ in most patients, excluding plasma sodium as a causative factor.

In the placebo-controlled, randomized pilot study, max delta- $\delta \mathrm{P}$ was not different in children who received the noncompetitive N-methyl-D-aspartate receptor antagonist dextromethorphan. Therefore, we have no indications that the N-methyl-Daspartate receptor is involved in the generation of postoperative slow wave activity (12).

Intraoperative variables are suspected to influence the postoperative EEG. Duration of CPB and AC correlates with the risk for neurologic sequelae (25), and we expected a corresponding increase of $\delta \mathrm{P}$. Our data, however, showed an opposite association, excluding $\mathrm{CPB}$ and $\mathrm{AC}$ as causative factors for postoperative EEG slowing. Intraoperative cerebral complications, obvious by normothermic isoelectric EEG $>50$ s, resulted in neurologic deficits in all affected children, but none of them showed a relevant increase of postoperative $\delta \mathrm{P}$.

After surgery, brain injury might occur when energy supply is compromised by cardiopulmonary dysfunction (5). However, in our study, half of the patients with cardiopulmonary dysfunctions had no or minimal increase of $\delta \mathrm{P}$, whereas almost all children without such complications had distinct increase of $\delta \mathrm{P}$.

An important aim of our study was to investigate oxidative stress and the inflammatory response as possible causative factors for postoperative EEG slowing. Both are triggered by cardiac surgery with CPB $(7,26,27)$ and suspected to contribute to the postoperative neurologic dysfunctions $(6,28)$. We expected $\delta \mathrm{P}$ to increase when oxidative stress (e.g. loss of the plasma antioxidant ascorbate) or the inflammatory response was high. However, it is intriguing that we found the opposite to be the case. Both the loss of ascorbate and postoperative levels of IL- 6 and IL- 8 negatively correlated with delta- $\delta$ P. To the best of our knowledge, this is the first study that looked for possible associations of EEG changes with oxidative stress/ inflammation. Other pediatric systemic diseases of either infectious $(29,30)$ or noninfectious (31) origin have been reported to show distinct temporary EEG slowing. In these studies, EEG slowing also mostly coincided without neurologic symptoms and sequelae. In septic encephalopathy, however, slow wave activity correlated with the severity of the clinical course (32). The reason for the EEG slowing is unknown.

Criticism of methods. Our cohort included heterogeneous congenital heart diseases with a wide age range and different surgical approaches. Risk factors that apply to specific types of heart disease or surgery might have been missed because the respective number of children was too small. Age and maturity of the brain (obviously) affect the postoperative EEG changes and might influence the correlation analysis between EEG and other perioperative variables. By excluding neonates, the reliability of the EEG analysis improved but did not eliminate the age factor completely.

Visual rating of EEG by experienced EEG technicians is widely accepted to quantify abnormalities and change of background activity $(10,11,14,21)$. FFT data, however, are more suitable for statistical analysis and detailed presentation of the postoperative EEG. Rating and FFT data correlate well in our study and confirm the reliability of both methods.

Mean values of delta- $\delta \mathrm{P}$, calculated over 500 epochs, are useful to display the postoperative course of EEG. For statistical comparison with intra- and postoperative variables, however, single mean values might be distorted by short-term artifacts. Twelve-hour means of delta- $\delta \mathrm{P}$ avoid such distortion but also smooth the peaks of delta- $\delta$ P. Movement artifacts and different vigilant states during the preoperative registration are another critical point. Although substantial efforts were undertaken to extract artifact-free sequences from the preoperative EEG, vigilant states were sometimes difficult to determine and probably not comparable in all children.

Sedative and analgesics might have had an influence on EEG. Benzodiazepines and opioids increase delta activity at high doses (33-35). Dosing in our patients was within the recommended range, and at the time of EEG slowing dosing was usually lower than during surgery and during the first postoperative hours. We could not exclude elevated drug levels caused by drug interaction or compromised metabolism. These factors, however, should be more relevant when intra- and postoperative complications occur. The absent increase of slowing in half of our patients with postoperative complications and the inverse association with the duration of postoperative ventilation points against compromised drug metabolism as causative factors for the observed EEG slowing. Nevertheless, we could not completely exclude drug influences on the postoperative EEG in our study. In neonates, morphine produces prolonged periods of electrical quiescence and interictal epileptiform activity (36). Postoperative periodic pattern and increase of spike wave activity in our neonates might be partly caused by morphine and reduce the clinical significance of the EEG changes.

Neurodevelopmental studies before and after cardiac surgery are confronted with several problems. Children are often ill before surgery, preventing developmental assessment. Even in healthy infants, functional testing is limited in terms of scope and predictive validity for later outcome (37). Many functions that are required for learning complex skills in later childhood could not be tested at this age. Corresponding deficits cannot be attributed beyond doubt to intraoperative damage (37). Genetic and environmental factors potentially also contribute to the cognitive development of children who are born with congenital heart disease and subsequently undergo elective heart surgery (38). Combined cardiac and neurologic manifestations are prevalent in certain chromosomal and inherited 
metabolic disorders (39). Although we have excluded children with obvious neurologic and chromosomal abnormalities, some of these factors might have influenced the neurodevelopmental outcome in our study. However, individual differences between pre- and postoperative developmental score might be less affected by these factors when established in the time frame of our observation period.

Comment. We cannot provide etiologic explanations for the appearance of slow wave activity, occurring several hours after surgery and persisting for several days. Our data, however, give some indication that events that affect the brain might inhibit the postoperative increase of $\delta \mathrm{P}$. This would suggest a more positive view of the postoperative EEG slowing.

Slow wave activity reflects a functional state of neurons and the neuronal network that is triggered not only by pathophysiologic events. After CPB, most neuronal and other dysfunctions are transitory and might be caused by imbalances of metabolism and ions, rather than by injury. The postoperative slowing could be a step in the transition from dysfunction to recovery. Physiologic slow waves are part of the non-rapid eye movement sleep, which has important functions for the maintenance of brain integrity (40). It might be speculated that similar mechanisms are used for the brain recovery after CPB. The understanding of the physiologic or pathophysiologic mechanisms behind the early postoperative EEG changes might provide further insights into the cerebral processes that occur during and after CPB.

Acknowledgments. Careful technical assistance by Corinne Huber, Irene Knaus, Roberta Carrachini, and Ruth Sidler is acknowledged. We thank Drs. Felicitas Steiner and Gabriele Wohlrab, who carried out the developmental tests, and Dr. Manfred Spueler (IT-med) for technical advice.

\section{REFERENCES}

1. Ferry PC 1990 Neurologic sequelae of open-heart surgery in children. An 'irritating question.' Am J Dis Child 144:369-373

2. Bellinger DC, Wypij D, Kuban KC, Rappaport LA, Hickey PR, Wernovsky G, Jonas RA, Newburger JW 1999 Developmental and neurological status of children at 4 years of age after heart surgery with hypothermic circulatory arrest or low-flow cardiopulmonary bypass. Circulation 100:526-532

3. Hovels-Gurich HH, Seghaye MC, Schnitker R, Wiesner M, Huber W, Minkenberg R, Kotlarek F, Messmer BJ, Von Bernuth G 2002 Long-term neurodevelopmental outcomes in school-aged children after neonatal arterial switch operation. J Thorac Cardiovasc Surg 124:448-458

4. Robertson CM, Joffe AR, Sauve RS, Rebeyka IM, Phillipos EZ, Dyck JD, Harder JR; The Western Canadian Complex Pediatric Therapies Project Follow-up Group 2004 Outcomes from an interprovincial program of newborn open heart surgery. J Pediatr 144:86-92

5. du Plessis AJ 1999 Mechanisms of brain injury during infant cardiac surgery. Semin Pediatr Neurol 6:32-47

6. Paparella D, Yau TM, Young E 2002 Cardiopulmonary bypass induced inflammation: pathophysiology and treatment. An update. Eur J Cardiothorac Surg 21:232-244

7. Matata BM, Sosnowski AW, Galinanes M 2000 Off-pump bypass graft operation significantly reduces oxidative stress and inflammation. Ann Thorac Surg 69:785-791

8. Mezrow CK, Midulla PS, Sadeghi AM, Gandsas A, Wang W, Dapunt OE, Zappulla R, Griepp RB 1994 Evaluation of cerebral metabolism and quantitative electroencephalography after hypothermic circulatory arrest and low-flow cardiopulmonary bypass at different temperatures. J Thorac Cardiovasc Surg 107:1006-1019

9. O'Hare B, Bissonnette B, Bohn D, Cox P, Williams W 1995 Persistent low cerebral blood flow velocity following profound hypothermic circulatory arrest in infants. Can J Anaesth 42:964-971

10. Sotaniemi KA 1980 Clinical and prognostic correlates of EEG in open-heart surgery patients. J Neurol Neurosurg Psychiatry 43:941-947

11. Limperopoulos C, Majnemer A, Rosenblatt B, Shevell MI, Rohlicek C, Tchervenkov C, Gottesman R 2001 Association between electroencephalographic findings and neurologic status in infants with congenital heart defects. J Child Neurol 16:471-476
12. Schmitt B, Bauersfeld U, Fanconi S, Wohlrab G, Huisman TA, Bandtlow C, Baumann P, Superti-Furga A, Martin E, Arbenz U, Molinari L, Turina M, Boltshauser E, Schmid ER 1997 The effect of the N-methyl-D-aspartate receptor antagonist dextromethorphan on perioperative brain injury in children undergoing cardiac surgery with cardiopulmonary bypass: results of a pilot study. Neuropediatrics 28:191-197

13. Schmitt B, Bauersfeld U, Schmid ER, Tuchschmid P, Molinari L, Fanconi S, Bandtlow C 1998 Serum and CSF levels of neuron-specific enolase (NSE) in cardiac surgery with cardiopulmonary bypass: a marker of brain injury? Brain Dev 20:536539

14. Sarnat HB, Sarnat MS 1976 Neonatal encephalopathy following fetal distress. A clinical and electroencephalographic study. Arch Neurol 33:696-705

14a. Christen S, Finckh B, Lykkesfeldt J, Gessler P, Frese-Schaper M, Nielsen P, et al 2005 Oxidative stress precedes peak systemic inflammatory response in pediatric patients undergoing cardiopulmonary bypass operation Free Radic Biol Med 38:1323-1332

15. Brandt I 1983 Entwicklungsskalen (GES) zur Beurteilung der Entwicklung in den ersten beiden Lebensjahren. Beltz Verlag, Basel

16. Griffiths R 1970 Abilities of Young Children. A Comprehensive System of Mental Measurement for the First Eight Years of Life. Young and Son, London

17. Tellegen PJ, Winkel M, Wijnberg-Williams BJ 1996 Snijders-Oomen Non-verbaler Intelligenztest SON-R 21/2-7. Swets \& Zeitlinger, Amsterdam/Lisse

18. Lykkesfeldt J 2000 Determination of ascorbic acid and dehydroascorbic acid in biological samples by high-performance liquid chromatography using subtraction methods: reliable reduction with tris[2-carboxyethyl]phosphine hydrochloride. Anal Biochem 282:89-93

19. Fukunaga K, Suzuki T, Takama K 1993 Highly sensitive high-performance liquid chromatography for the measurement of malondialdehyde in biological samples. J Chromatogr 621:77-81

20. Pampiglione G 1965 Electroencephalographic and metabolic changes after surgical operations. Lancet 19:263-265

21. Sachdev NS, Carter CC, Swank RL, Blachly PH 1967 Relationship between postcardiotomy delirium, clinical neurological changes, and EEG abnormalities. J Thorac Cardiovasc Surg 54:557-563

22. Hauser E, Seidl R, Rohrbach D, Hartl I, Marx M, Wimmer M 1993 Quantitative EEG before and after open heart surgery in children. A significant decrease in the beta and alpha 2 bands postoperatively. Electroencephalogr Clin Neurophysiol 87:284-290

23. Holmes GL, Lombroso CT 1993 Prognostic value of background patterns in the neonatal EEG. J Clin Neurophysiol 10:323-352

24. Helmers SL, Wypij D, Constantinou JE, Newburger JW, Hickey PR, Carrazana EJ, Barlow JK, Kuban KC, Holmes GL 1997 Perioperative electroencephalographic seizures in infants undergoing repair of complex congenital cardiac defects. Electroencephalogr Clin Neurophysiol 102:27-36

25. Brown WR, Moody DM, Challa VR, Stump DA, Hammon JW 2000 Longer duration of cardiopulmonary bypass is associated with greater numbers of cerebral microemboli. Stroke 31:707-713

26. Gessler P, Pfenninger J, Pfammatter JP, Carrel T, Baenziger O, Dahinden C 2003 Plasma levels of interleukin- 8 and expression of interleukin-8 receptors on circulating neutrophils and monocytes after cardiopulmonary bypass in children. $\mathbf{J}$ Thorac Cardiovasc Surg 126:718-725

27. Ballmer PE, Reinhart WH, Jordan P, Buhler E, Moser UK, Gey KF 1994 Depletion of plasma vitamin $\mathrm{C}$ but not of vitamin $\mathrm{E}$ in response to cardiac operations. $\mathrm{J}$ Thorac Cardiovasc Surg 108:311-320

28. Clancy RR, McGaurn SA, Goin JE, Hirtz DG, Norwood WI, Gaynor JW, Jacobs ML, Wernovsky G, Mahle WT, Murphy JD, Nicolson SC, Steven JM, Spray TL 2001 Allopurinol neurocardiac protection trial in infants undergoing heart surgery using deep hypothermic circulatory arrest. Pediatrics 108:61-70

29. Onoe S, Nishigaki T 2004 EEG spectral analysis in children with febrile delirium. Brain Dev 26:513-518

30. Moura Ribeiro V, Moura Ribeiro R 1968 Evolutive aspects in the EEGs of patients with measles and no neurological signs. Dev Med Child Neurol 10:175-179

31. Eriksson KJ, Boyd SG, Tasker RC 2001 Acute neurology and neurophysiology of haemolytic-uraemic syndrome. Arch Dis Child 84:434-435

32. Young GB, Bolton CF, Archibald YM, Austin TW, Wells GA 1992 The electroencephalogram in sepsis-associated encephalopathy. J Clin Neurophysiol 9:145-152

33. Sloan TB 1998 Anesthetic effects on electrophysiologic recordings. J Clin Neurophysiol 15:217-226

34. Sebel PS, Bovill JG, Wauquier A, Rog P 1981 Effects of high-dose fentanyl anesthesia on the electroencephalogram. Anesthesiology 55:203-211

35. Smith NT, Dec-Silver H, Sanford TJ Jr, Westover CJ Jr, Quinn ML, Klein F, Davis DA 1984 EEGs during high-dose fentanyl-, sufentanil-, or morphine-oxygen anesthesia. Anesth Analg 63:386-393

36. Young GB, da Silva OP 2000 Effects of morphine on the electroencephalograms of neonates: a prospective, observational study. Clin Neurophysiol 111:1955-1960

37. Bellinger DC 2003 Cardiac surgery and the brain: differences between adult and paediatric studies. Heart 89:365-366

38. Forbess JM, Visconti KJ, Hancock-Friesen C, Howe RC, Bellinger DC, Jonas RA 2002 Neurodevelopmental outcome after congenital heart surgery: results from an institutional registry. Circulation 106:I95-I102

39. du Plessis AJ 1997 Neurologic complications of cardiac disease in the newborn. Clin Perinatol 24:807-826

40. Hairston IS, Knight RT 2004 Neurobiology: sleep on it. Nature 430:27-28

41. Bayley N 1993 Bayley Scales of Infant Development. The Psychological Corporation, San Antonio, TX 